\title{
A comparison of patients dying at home and patients dying at a hospice: Sociodemographic factors and caregivers' experiences
}

\author{
MARIA E. CARLSSON, B.A., DR. MED. SC., S.R.N., ${ }^{1}$ \\ AND BRITTA ROLLISON S.R.N. ${ }^{2}$ \\ ${ }^{1}$ Department of Public Health and Caring Sciences, Uppsala University, Uppsala, Sweden \\ ${ }^{2}$ Kronparkens sjukhem, Eva Lagerwalls väg 1, Uppsala, Sweden
}

(RECEIVEd September 30, 2002; AcCePted December 20, 2002)

\begin{abstract}
Objective: The aim of this study was to investigate whether there were any differences between patients who died at home and patients who died at a hospice, that is, sociodemographic variables, the family caregivers' experiences of burden, and their opinion of reasons for hospice care.

Methods: The study comprises a consecutive sample of family caregivers to adult patients: (I) who were cared for by the advanced palliative home care team (APHCT) and died at home, (II) who were cared for by the APHCT and died at the Hospice, (III) who were cared for and died at the Hospice in Uppsala during a period of one year. A questionnaire was mailed to caregivers and the medical records of all the patients were analyzed.

Results: The place of death differed significantly and varied according to gender and cohabitation status. Men died to a greater degree at home compared with women. The family caregivers' experiences of burden were moderate. Caregivers of patients who died at home thought that this care form has a more positive influence on the patients' quality of life than was the case in the other groups. They were also more satisfied with their own achievement. The caregivers' opinion of why patients needed hospice care was nearly the same in groups II + III, acutely developing symptoms being the most common reason.

Significance of results: This study showed that women died to a lesser degree at home than men. The explanation for this is unknown and requires further investigation. It is important to establish whether female patients or male caregivers need another type of support than male patients or female caregivers, since the aim of palliative care is that every patient who wishes to die at home should have this wish fulfilled.
\end{abstract}

KEYWORDS: Cancer, Caregiver, Palliative home care, Hospice care

\section{INTRODUCTION}

During the past decade it has become more common in Sweden for dying cancer patients to be offered home care by their relatives with the support of an

Corresponding author: Maria Carlsson, Department of Public Health and Caring Sciences, Uppsala University, Döbelnsgatan 2, SE 75237 Uppsala, Sweden. E-mail: maria. carlsson@pubmed.uu.se advanced palliative home care team (APHCT; BeckFriis \& Strang, 1993a). Many relatives and patients appreciate this opportunity to remain at home and be able to receive palliative care (Beck-Friis \& Strang, 1993b). In general, when home care is offered as a concrete option, patients and relatives are more satisfied with home care than with conventional care (Greer \& Mor, 1986; Seal, 1991; Hughes et al., 1992). The fundamental principle for successful palliative home care is that both patient 
and the family caregivers request the care model (Beck-Friis, 1993) and that the caregivers have the prerequisites to cope with the task. Otherwise, there is a risk that the caregiver will be overburdened by the responsibility and the physically and psychologically demanding tasks associated with caring for a dying person at home (Kristjanson, 1996; Szebehely, 1998). Family support has, in some studies, been identified as being the strongest independent factor associated with home death (De Conno et al., 1996; Thorén-Todoulos, 1999). Cantwell et al. (2000) showed that the strongest predictors related to dying at home are the patient's and the caregiver's desire for home death. The presence of more than one caregiver was another predictive factor. In the study by Gomas (1993), the most frequently reported reason for hospital admission was family exhaustion.

The only factor characteristic of home deaths in a rural district was a significantly smaller amount of home deaths when the interval from diagnosis to death was less than one month (Axelsson et al., 1996). A possible explanation for this is that both the patients and their families need time to comprehend the situation and to make arrangements. The organizational factor is also of importance for the potential number of patients dying at home. Wergeland Sørbye (1997) surveyed home deaths in Norway and found that there were few occurrences of home death in municipalities with a local hospital and good nursing homes capacity, and found no connection between well-developed home care and home deaths. In Sweden, on the other hand, more cancer patients died at home in places where a comprehensive organization of advanced palliative home care is available (SOU, 2000).

If the patient or the caregiver does not wish to have home care, or if home care is unsuitable for other reasons, institutional care at a hospice or other palliative in-patient unit remains an alternative. Some patients and caregivers are positive to home care but not to home death; they might have initially favored the concept of home death but alter this preference over time (Hinton, 1994). In these situations, a combination of home care and hospice care is optimal.

Some studies have investigated what patients and informal caregivers value in palliative care. It is essential that the relatives' experience of the patient's final days is as positive as possible since the relatives' health status after the patient's death correlates positively to their satisfaction with the quality of cares afforded (Fakhoury et al., 1997). A. Milberg, P. Strang, M. Carlsson, and S. Börjesson (submitted) showed that caregivers mainly emphasize the importance of staff competence and atti- tude, availability and security when defining "good palliative care."

In the Uppsala municipality, one specialized multiprofessional team serves the whole town and the immediate surroundings and is organized according to the Motala model (Beck-Friis, 1993). The APHCT provides mainly medical care and support. If the patients need help with the activities of daily living (ADL) they receive help from the local municipality home service (HS). The APHCT has access to back-up beds at the local hospice managed by the Uppsala County Council and these are available at short notice. Some patients previously cared for by other home care teams (i.e., Enköping and in North Uppland) can also be admitted to the Hospice. Patients are also admitted directly to the Hospice without any previous involvement from APHCT. Fürst (2000) gives a comprehensive description of the development and organization of palliative care in Sweden.

This study focused mainly on the following questions:

1. Were there any sociodemographic differences between patients who died at home and patients who died at the Hospice?

2. Were there any differences between experiences of burden and accomplishment in family caregivers to patients who died at home and those of patients who died at the Hospice?

3. What were the family caregivers' opinions of the reasons for choosing hospice care?

\section{MATERIAL AND METHODS}

The medical records of all patients who died at the Hospice ward or at home under the care of the APHCT during one year were analyzed to ascertain the diagnosis, the place of death, the care period, and sociodemographic factors. The data from the medical records provided answers to question 1 .

The study population also consisted of a consecutive sample of one family caregiver to each adult patient who was cared for by the APCHT and who died at home and one caregiver to each adult patient who was cared for and died at the Hospice in Uppsala during one year. Three different conditions were possible.

I. Caregivers to patients who were cared for by APHCT and died at home;

II. Caregivers to patients cared for by APHCT (or another home care team) and the Hospice and who died at the Hospice;

III. Caregivers to patients who were cared for and died at the Hospice. 
The APHCT and Hospice staff identified the caregiver who had been most involved in the patient's care. Caregivers were contacted over the telephone and given information about the study and assured that data would be handled by a person (MC) with no involvement in the patient's care. The questionnaire was designed specifically for this study and the questions were selected on the basis of results of earlier studies (Beck-Friis \& Strang, 1993b; Rollison \& Carlsson, 2002) and a comprehensive review of the literature (SOU, 2000). Thus, questions were expected to have an acceptable degree of content validity. The questions were either dichotomized (yes/no) or had a 5-point scale. All caregivers were asked to answer demographic questions. The questionnaire accompanied by written information was sent by mail 2-4 months after bereavement. Those who did not respond to the first letter were sent a reminder. The questions in the questionnaire provide answers to the second and the third questions. The questions dealt with background data covering the care situation $(n=5)$, caregivers' experiences of burden during the home care period $(n=6)$, caregivers' experiences of accomplishment $(n=2)$, if relatives could be replaced when desired $(n=1)$, and caregivers' opinion of why patients needed hospice care $(n=1)$. The Ethical Committee of the Uppsala University approved the study.

Statistical comparisons between groups were conducted with chi-squared test or nonparametric test such as Mann-Whitney $U$ test or KruskalWallis depending on the type of variables (Howell, 1992). To ascertain the difference between genders, a control for living was performed by configuration analysis (Cairns \& Bergman, 1998). The statistics were computed using SPSS software. In the Results section some mean values are presented for a greater clarity, although the MannWhitney $U$ test or Kruskal-Wallis were used for the statistical calculations.

\section{RESULTS}

During the study period, a total of 116 patients were cared for by the APHCT and died; 63 died at home, 49 died at the Hospice, 3 at other departments of the University hospital, and 1 in another country. Six patients were excluded by the staff, mainly because of the short care period, and were not provided with a questionnaire. Fifty of the caregivers of patients who died at home answered the questionnaire: this represented a response rate of $78 \%$.

During the period, 118 patients died at the Hospice. Two patients who died at the Hospice had been cared for by another home care team than APHCT in Uppsala and are included in group III. Eighteen patients were excluded by the staff, mainly because they had no caregivers, the caregivers could not been reached by telephone, or the caregiver refused participation on telephone. Eighty relatives answered the questionnaire, a response rate of $68 \%$.

A breakdown of the sample into demographic characteristics for the patients is shown in Table 1 and for participating caregivers in Table 2. The period of home care varied from 1 to 365 days $(M=$ 62 , median $=36$ ). The care period at the Hospice varied from 1 to 179 days and the average time was nearly the same for group II $(M=27$, median $=8.5)$ and group III $(M=20$, median $=9)$. The dropouts in patient group I were mostly women $(71 \%)$ who cohabited $(90 \%)$, in group II 50\% women and men mostly cohabited (75\%), and in group III men (58\%) who lived alone (54\%). The age patterns were nearly the same in the respondent group and in the dropout group.

The place of death differed significantly depending on gender and on whether the patient was living with a cohabitant. Men died to a greater

Table 1. Demographic data (from medical records)

\begin{tabular}{|c|c|c|c|}
\hline Characteristic & $\begin{array}{l}\text { Group I } \\
(n=63)\end{array}$ & $\begin{array}{l}\text { Group II } \\
(n=51)\end{array}$ & $\begin{array}{l}\text { Group III } \\
(n=69)\end{array}$ \\
\hline \multicolumn{4}{|l|}{ Diagnosis } \\
\hline Breast cancer & 5 & 8 & 6 \\
\hline Urological cancer & 13 & 10 & 8 \\
\hline Gynaecologic cancer & 9 & 5 & 3 \\
\hline Gastrointestinal cancer & 20 & 13 & 25 \\
\hline Lung cancer & 4 & 1 & 13 \\
\hline Brain tumor & 4 & 3 & 2 \\
\hline Unknown cancer & 3 & 1 & 4 \\
\hline Not cancer & 1 & 3 & 0 \\
\hline Leukaemia, lymphoma & 6 & 2 & 3 \\
\hline Other cancer diagnosis & 4 & 6 & 5 \\
\hline \multicolumn{4}{|l|}{ Gender } \\
\hline Men & 41 & 23 & 28 \\
\hline Women & 22 & 28 & 38 \\
\hline \multicolumn{4}{|l|}{ Age (years) } \\
\hline Mean & 66.5 & 70 & 70 \\
\hline Range & $18-86$ & $35-90$ & $33-89$ \\
\hline \multicolumn{4}{|l|}{ Living } \\
\hline Alone & 9 & 24 & 36 \\
\hline Cohabiting & 52 & 23 & 30 \\
\hline \multicolumn{4}{|c|}{ Duration of contact with AHC (days) } \\
\hline Range & $1-201$ & $1-365$ & 0 \\
\hline Median & 29 & 50 & 0 \\
\hline Mean & 52 & 74 & 0 \\
\hline \multicolumn{4}{|c|}{ Duration of contact with Hospice (days) } \\
\hline Range & 0 & $1-145$ & $1-179$ \\
\hline Median & 0 & 8.5 & 9 \\
\hline Mean & 0 & 27 & 20 \\
\hline
\end{tabular}


Table 2. Demographic data about the response group (relatives) (from questionnaire)

\begin{tabular}{lccc}
\hline \hline Characteristic & $\begin{array}{c}\text { Group I } \\
(n=50)\end{array}$ & $\begin{array}{c}\text { Group II } \\
(n=35)\end{array}$ & $\begin{array}{c}\text { Group III } \\
(n=45)\end{array}$ \\
\hline Gender & & & \\
$\quad$ Men & 16 & 14 & 19 \\
$\quad$ Women & 33 & 21 & 26 \\
Age & & 59 & 60 \\
$\quad$ Mean & 61 & $25-88$ & $22-88$ \\
$\quad$ Range & $32-84$ & & \\
Home service & & 21 & 16 \\
$\quad$ Yes & 24 & 14 & 24 \\
No & 20 & 0 & 5 \\
$\quad$ Missing data & 6 & & \\
\hline \hline
\end{tabular}

degree at home than women (chi-square $=7.57$, $d f=1, p<.01$ ), both when comparing the whole group $(n=181)$ and when comparing the subgroup patients (groups I and II), who were cared for by a home care team $(n=113$; chi-square $=4.13, d f=1$, $p<.05$ ). Living with a cohabitant refers to patients living with a partner, adult children, or parents. Home deaths were significantly higher in the cohabitant group than in the group living alone, both when comparing the whole group (chi-square = $17.63 d f=1, p<.0001$ ) and the subgroup cared for by a home care team (chi-square $=6.74, d f=1, p<$ .01). To ascertain the difference between genders, a study of the forms under which patients lived was performed by a configuration analysis. The analysis of the whole group $(n=181)$ gave three patterns. Fewer women who lived alone died at home than expected (chi-square $=7.05, d f=2, p<.05$ ), more women who lived alone died at the Hospice than expected (chi-square $=7.24, d f=2, p<.05$ ), and more cohabiting men died at home than expected (chi-square $=9.26, d f=2, p<.05$ ).

When asked if the caregivers could be replaced when desired, $84 \%$ in group I, $74 \%$ in group II and $59 \%$ in group III stated that they could (chi-square = $7.39, p<.05)$. The caregivers' experiences of burden during the home care period are summarized in Table 3. Three significant differences were identified between the three groups. The caregivers in group I had a greater sleeping deficit than the other groups (chi-square $=13.01, p<.001$ ), the caregivers in group III felt a bigger responsibility overload for home care than group I ( $z$ value $=$ $-2.188, p<.05)$ and the caregivers in group I experienced home care to be more physically burdensome than the caregivers in group III $(z$ value $=$ $-2.413, p<.05)$.

The caregivers' experiences of accomplishment also differed according to subgroups (Table 4). The question "How was a patient's quality of life affected by providing care at home or in the Hospice?" refers to the place of death (Table 4). Caregivers to patients in group I thought that the patient's quality of life was affected in a more positive way depending on the form of care, compared with the perceptions of caregivers to patients in groups II and III (chi-square $=21.511, d f=2, p<.0001$ ).

When comparing the caregivers' situation at home, based on gender, two significant differences were found. Female caregivers experienced home care to be more physically burdensome than men $(z$ value $=-2.349, p<.05$ ). However, female caregivers also were more satisfied with own achievements than male $(z$ value $=-2.059, p<.05)$.

There were also some significant differences when comparing caregivers to the groups living together with the patient and caregivers to patients living alone. Caregivers living with the patients ranked

Table 3. Relative's experiences of burden during the home care period ${ }^{\text {a }}$

\begin{tabular}{|c|c|c|c|c|c|c|}
\hline \multirow[b]{2}{*}{ Topic } & \multicolumn{2}{|c|}{ Group I } & \multicolumn{2}{|c|}{ Group II } & \multicolumn{2}{|c|}{ Group III } \\
\hline & $\begin{array}{c}M \\
(n=50)\end{array}$ & $\begin{array}{l}\text { Missing } \\
(n)\end{array}$ & $\begin{array}{c}M \\
(n=35)\end{array}$ & $\begin{array}{l}\text { Missing } \\
(n)\end{array}$ & $\begin{array}{c}M \\
(n=45)\end{array}$ & $\begin{array}{l}\text { Missing } \\
(n)\end{array}$ \\
\hline Homebound & 3.35 & (10) & 3.33 & (5) & 3.26 & (14) \\
\hline Isolated at home & 2.44 & (2) & 2.50 & (5) & 2.58 & (14) \\
\hline Physically burdensome & $2.69^{*}$ & (1) & 2.66 & (6) & 2.03 & (15) \\
\hline Psychologically burdensome & 3.47 & (1) & 3.60 & (5) & 3.71 & (14) \\
\hline Responsibility overload & 2.41 & (1) & 2.75 & (3) & $3.06^{*}$ & (14) \\
\hline Sleeping deficit & $3.73^{*}$ & (2) & 2.93 & (5) & 2.74 & (14) \\
\hline
\end{tabular}

aA higher score represents a higher level of burden ( 1 = "nothing," 2 = "negligible," 3 = "moderate," $4=$ "quite large," 5 = "considerable"). The internal dropout was quite high in group III.

$* p<.05$ 
Table 4. Relatives' experiences of accomplishment

\begin{tabular}{|c|c|c|c|c|c|c|}
\hline \multirow[b]{2}{*}{ Topic } & \multicolumn{2}{|c|}{ Group I } & \multicolumn{2}{|c|}{ Group II } & \multicolumn{2}{|c|}{ Group III } \\
\hline & $\begin{array}{c}M \\
(n=50)\end{array}$ & $\begin{array}{l}\text { Missing } \\
\quad(n)\end{array}$ & $\begin{array}{c}M \\
(n=35)\end{array}$ & $\begin{array}{l}\text { Missing } \\
\quad(n)\end{array}$ & $\begin{array}{c}M \\
(n=45)\end{array}$ & $\begin{array}{l}\text { Missing } \\
\quad(n)\end{array}$ \\
\hline Satisfied with own achievement & $4.07 * *$ & (4) & 3.34 & $(3)$ & 3.53 & (15) \\
\hline $\begin{array}{l}\text { How patient's QOL was affected } \\
\text { by giving care at home or hospice }\end{array}$ & $4.78 * * *$ & (5) & 3.91 & $(2)$ & 4.19 & $(2)$ \\
\hline
\end{tabular}

aA higher score represents a higher level of burden $(1=$ "nothing," $2=$ "negligible," $3=$ "moderate," $4=$ "quite large," $5=$ "considerable").

$* * p<.01 ; * * * p<.0001$.

the physical burden $(z$ value $=-3.562, p<.0001)$ and sleeping deficit $(z$ value $=-2.019, p<.05)$, higher than the "living alone group."

The caregivers' opinions of why patients needed the hospice care were almost the same in groups II and III (Table 5). Acute symptoms were the most common reason in group II (80\%) and group III (52\%). Long-lasting symptoms were the second most frequent reason in group III (31\%) but this reason was rare in group II (5.7\%).

\section{DISCUSSION}

An interesting finding in this study was that men died to a greater degree at home than women and women died at the Hospice more often than men. This pattern is in accordance with other studies (Hunt et al., 1990; De Conno et al., 1996; Andershed \& Ternestedt, 1997) One hypothesis is that this difference reflects the fact that men more often have a wife that can provide primary care. In this study this hypothesis was not confirmed since the

Table 5. Relative's view of why patients needed hospice care $^{\mathrm{a}}$

\begin{tabular}{lcrr}
\hline \hline & $\begin{array}{c}\text { Group } \\
\text { II }\end{array}$ & $\begin{array}{c}\text { Group } \\
\text { III }\end{array}$ \\
Reason for hospice care & $(n=35)$ & $(n=45)$ & Total \\
\hline Patients' wish & 11 & 9 & 20 \\
Acute symptoms & 28 & 23 & 51 \\
Long-lasting symptoms & 2 & 14 & 15 \\
No relative at home & 1 & 4 & 5 \\
Relatives' own health problems & 1 & 2 & 3 \\
Relatives' exhaustion & 7 & 6 & 13 \\
Other reasons & 4 & 6 & 10 \\
Total & 64 & 54 & \\
& & &
\end{tabular}

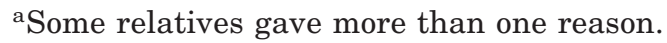

difference remained after controlling for cohabitant. The pattern is the same as that found in the care of elderly, where more women than men lived in nursing homes or other institutions measured in relation to the number of women and men in the population (Szebehely, 1998). Szebehely (1998) discussed this topic and one theory is that wives and daughters are better caregivers than husbands and sons and therefore access to a wife or daughter protects against in-patient care. In conflict with this argument is the fact that there is a shortage of in-patient care, which relatives must often negotiate. Maybe the relevant question is whether husbands and sons are better "solicitors" or "negotiators" for their wives or mothers (Johansson, 1998).

We did not think that the latter argument is applicable to this study, because caregivers to patients who died at home thought that the patients' quality of life was affected in a more positive way depending on the form of care than caregivers to patients who died at the Hospice. They were also more satisfied with their own achievement. That women were more satisfied with their own achievement than men maybe reflects the fact that more men than women died at home and hence more women than men were caregivers to patients who died at home. However, it is important to remark that the dropout rate in group I, mostly female patients $(71 \%)$, might distort the results. In spite of this, the results indicate that caregivers' impressions were that home death was preferable and this opinion is in accordance not only with that of the general public (Ashby \& Wakefield, 1993; Landstingsförbundet, 1998; SOU, 2001) but also with that of cancer patients in general (Dunlop et al., 1989; Townsend et al., 1990).

The caregivers' experience of burden was moderate. The highest scores measured occurred in group I, who experienced a high degree of sleeping deficit (3.73), and group III, who perceived home care to be psychologically burdensome (3.71). The sleeping deficit was significantly higher in group I than in the 
other subgroups; this relationship to the place of death was not demonstrated in Bramwell et al.'s (1995) study. Dying people's needs for physical assistance are greatest during the last weeks (Axelsson \& Sjödén, 1998), while patients in groups II and III were cared for at the Hospice, and this circumstance may explain the difference. That caregivers suffered from sleeping deficit has also been shown in previous studies (Jones et al., 1993; Bramwell et al., 1995; Axelsson \& Sjödén, 1998; Rollison \& Carlsson, 2002). That relatives in group III perceived the period at home to be quite psychologically burdensome might reflect the fact that these caregivers did not receive support from or share the caring with an APHCT, which has been identified as a crucial component in the caregiver's satisfaction with APHCT (Milberg et al., 2002). The difference was, however, not significant when compared with the other groups. However, group III perceived to a greater extent than group I that the responsibility for the care at home was too high. It is important to comment on the quite large numbers of missing data in group III. A possible explanation for this is that caregivers in that group did not consider that they had cared for the patient at home.

It is interesting to notice that the care period at the Hospice did not differ between patients previously cared for by APHCT (group II) and those admitted directly to the Hospice (group III). The period of care was nearly half the time reported in Andershed and Ternestedt's (1997) study (9 vs. 16.5 days). Why group III died so soon after final admission to the Hospice is an interesting question to investigate further. Had their conditions deteriorated very rapidly, had the palliative tumor-specific treatment been sustained too long or did this reflect a lack of Hospice beds? The short period of care together with the caregivers' reasons for admission to the Hospice, that $31 \%$ of the patients in group III had long-lasting symptoms, indicated that patients in group III probably would have benefited from some kind of palliative care or from a earlier referral to the Hospice.

\section{ACKNOWLEDGMENTS}

This study was supported by a grant from the Lisa Eriksson Foundation. Dr. Henry Letocha is acknowledged for skillful linguistic revision.

\section{REFERENCES}

Andershed, B. \& Ternestedt, B.M. (1997). Patterns of care for patients with cancer before and after the establishment of a hospice ward. Scandinavian Journal of Caring Sciences, 11, 42-50.
Ashby, M. \& Wakefield, M. (1993). Attitudes to some aspects of death and dying, living wills and substituted health care decision-making in South Australia: Public opinion survey for a parliamentary selected committee. Palliative Medicine, 7, 273-283.

Axelsson, B. \& Borup Christensen, S. (1996). Place of death correlated to sociodemographic factors. A study of 203 patients dying of cancer in a rural Swedish county in 1990. Palliative Medicine, 10, 329-335.

Axelsson, B. \& Sjödén, P.O. (1998). Quality of life of cancer patients and their spouses in palliative home care. Palliative Medicine, 12, 29-39.

Beck-Friis, B. (1993). Hospital-based home care of terminally ill cancer patients. The Motala model. Thesis, Uppsala University.

Beck-Friis, B. \& Strang, P. (1993a). The organization of hospital-based home care for terminally ill cancer patients: The Motala model. Palliative Medicine, 7, 93-100.

Beck-Friis, B. \& Strang, P. (1993b). The family in hospitalbased home care with special reference to terminally ill cancer patients. Journal of Palliative Care, 9, 1-9.

Bramwell, L., Mac Kenzie, J., Lashinger, H., \& Cameron, N. (1995). Need for overnight respite for primary caregivers of hospice clients. Cancer Nursing, 18, 337-343.

Cairns, R. \& Bergman, L. (1998). Methods and Models for Studying the Individual. Thousand Oaks, CA: Sage Publications, Inc.

Cantwell, P., Turco, S., Brenneis, C., Hanson, J., Neumann, C., \& Bruera, E. (2000). Predictors of home care death in palliative care cancer patients. Journal of Palliative Care, 16, 23-28.

De Conno, F., Caraceni, A., Groff, L., Brunelli, C., Donati, I., Tamburini, M., \& Ventafridda, V. (1996). Effect of home care on the place of death of advanced cancer patients. European Journal of Cancer, 32A, 1142-1147.

Dunlop, R., Davies, R., \& Hockely, J. (1989). Preferred versus actual place of death: A hospital palliative care support team experience. Palliative Medicine, 3, 197201.

Fakhoury, W., McCarty, M., \& Addington-Hall, J. (1997). Carers' health status: Is it associated with their evaluation of the quality of palliative care? Scandinavian Journal of Social Medicine, 25, 296-301.

F ürst, C.J. (2000). Perspectives on palliative care: Sweden. Supportive Care in Cancer, 8, 441-443.

Gomas, J. (1993). Palliative care at home: A reality or mission impossible? Palliative Medicine, 7(suppl. 3), 45-59.

Greer, D. \& Mor, V. (1986). An overview of National Hospice Study findings. Journal of Chronic Disease, $39,9-26$.

Hinton, J. (1994). Can home care maintain an acceptable quality of life for patients with terminal cancer and their relatives. Palliative Medicine, 8, 183-196.

Howell, D. (1992). Statistical Methods for Psychology. Belmont, CA: Duxbury Press.

Hughes, S., Cummings, J., Weaver, F., Manheim, L., Braun, B., \& Conrad, K. (1992). A randomized trial of cost effectiveness of VA hospital-based home care for the terminally ill. Health Services Research, 26, 801-817.

Hunt, R., Bonett, A., \& Roder, D. (1993). Trends in terminal care of cancer patients: South Australia, 19811990. Australian and New Zealand Journal of Medicine, 23, 245-251.

Johansson, L. (1998). Anhöriga som omsorgsgivare och omsorgsbehövande. In Äldreomsorgens vardag: en kon- 
ferens $i$ Göteborg 21-22 April 1998. Socialtjänstforum 3. Göteborg.

Jones, R.V.H., Hansford, J., \& Fiske, J. (1993). Death from cancer at home: The carers' perspective. British Medical Journal, 306, 249-251.

Kristjanson, L. (1996). Family members' perceptions of palliative cancer care: Predictors of family functioning and family members' health. Journal of Palliative Care, $12,10-20$.

Landstingsförbundet. (1998). Hemsjukvård-en annan dimension $i$ vården. Beställningsnr:1897.

Rollison, B. \& Carlsson, M. (2002). Evaluation of advanced home care (AHC). The next-of-kin's experiences. European Journal of Oncology Nursing, 6, 100-106.

Seale, C. (1991). A comparison of hospital and conventional care. Social Science and Medicine, 32, 147-152.

SOU. (2000). Utveckla kvaliteten i den palliativa vården. Bilaga till delbetänkandet döden angår oss alla-värdig värd vid livets slut. Statens offentliga utredningar 2000:6 Socialdepartementet.
SOU. (2001). Döden angår oss alla. Värdig vård vid livets slut. Slutbetänkande från kommittén om vård i livets slutskede. Statens offentliga utredningar 2001:6 Socialdepartementet.

Szebehely, M. (1998). Hustruns hjälp eller hemtjänstens? In Äldreomsorgens vardag: En konferens $i$ Göteborg 21-22 April 1998. Socialtjänstforum 3. Göteborg.

Thorén-Todoulos, E. (1999). Psykosociala faktorer begränsar möjligheten att dö hemma. Läkartidningen, 96, $472-475$.

Townsend, J., Frank, S., Fermont, D., Dyer, S., Karran, O., Walgrove, A., \& Piper, M. (1990). Terminal cancer care and patients' preferences for place of death: A prospective study. British Medical Journal, 301, 415-417.

Wergeland Sørbye, L. (1997). Cancer patients who prefer to die at home. Characterisations of municipalities with several of few occurrences of home deaths. Scandinavian Journal of Caring Sciences, 13, 102108. 